Original Research Paper

\title{
Theoretical Construction of Job Satisfaction of Workers of Creative Industries in Mexico City
}

\author{
María del Carmen López-García \\ Escuela Nacional de Medicina y Homeopatía, Instituto Politécnico Nacional, Mexico, Guillermo Massieu Helguera 239, \\ Fracc, La Escalera, Ticoman, C.P. 07320, Mexico City, Mexico
}

\author{
Article history \\ Received: $17-12-2020$ \\ Revised: 03-02-2021 \\ Accepted: 04-02-2021 \\ Email: mc.lpzg@gmail.com
}

\begin{abstract}
Job satisfaction is a concept studied since 1935 by both qualitative and quantitative studies. It is defined as a man's attitude towards his work. The objective of this study was to analyze the theoretical construction of job satisfaction that has been developed by the workers of the creative industries who live in Mexico City. The qualitative method of the informed theory was used. The sample was integrated by ten workers from various areas of the creative industries, working within the informal sector. In-depth interviews were conducted, which results were analyzed with the Atlas.ti program. 125 codes were found, which were grouped into six categories that eventually integrated the dimension of job satisfaction of these workers. The results show satisfaction elements that differ from those in the formal sector. Autonomy, achievements, recognition and personal realization are the predominant factors in the theoretical construction that these workers get from their job satisfaction.
\end{abstract}

\section{Keywords: Job Satisfaction, Ground Theory, Creative Industry}

\section{Introduction}

The creative industries are those that include the generation, production and distribution of goods and services related to design, music, literature, visual arts, performing arts, film, photography, video, architecture, publishing industry, bookstores, museums, galleries, radio, television, internet, advertising, festivals, fashion design, crafts, videogames, alternative media, among others (UNESCO Mexico, 2014).

These industries use intellectual capital as their main input and revalue attributes such as symbolism, beauty, originality and innovation. UNESCO believes that a country's investment in them promotes social development by contributing to overall well-being, improving selfesteem and quality of life and fostering dialogue and social cohesion (UNESCO Mexico, 2014). Also, because of its economic and social potential, the creative economy is promoted in different countries as an alternative to overcome capitalism and social difficulties (Gomes, 2018).

However and paradoxically, creative workers are in precarious conditions and most of them work within informality (independent work, underemployment). In other words, they do not have a "typical" work, which is carried out by work legislation. That means, with salary, guarantees and social benefits (medical care, insurance in case of an accident, among others) established in a collective contract.
This situation, as Gomes explains, is no coincidence, as the creative industries were promoted in the $1990 \mathrm{~s}$, when the economic development policies of neoliberalism arose in England, from where they were spread and adopted in different parts of the world (Gomes, 2018). Neoliberalism has provoked a declining state participation, a decrease in social spending, privatization, the lowering of high-income taxes, production globalization, a legislation that privileges the individual in detriment of the social, among other aspects.

According to García Canclini, young people are the ones who have mainly assumed the role of culture producers and consumers (García Canclini et al., 2012). Young people consume, create and communicate via unconventional networks. All this is done through selfemployment, stopping the current economic model to incorporate new generations into the labor market.

In Mexico, the 2020 National Occupation and Employment Survey shows that the informally employed population is represented by those who are professionally vulnerable because of the nature of the economic unit in which they work, whose employment link or dependence does not give them access to social security and/or those who are not recognized by their source of work. It includes self-employed people. This survey shows that in Mexico, 56.1\% (31.04 million) of the employed people during the first quarter of 2020 have an informal job (INEGI, 2020). 
Mexico, despite being a member of the OECD and as other Latin American countries, faces obstacles such as lack of investment, precarious infrastructure, little preparation in administrative aspects, lack of knowledge about contemporary cultural markets (national and international) and low political and financial support, to name a few (UNESCO Mexico, 2014).

Within this context, we find job satisfaction as a concept studied since 1935 , predominantly by quantitative studies and defined according to determinants of formal or "typical" work. One of the theories that underpin it is the one postulated by Maslow. He states that satisfaction is achieved by fulfilling the needs of an individual. He places these needs at various levels. On the basic levels, he places those related to physiological needs (hunger, thirst, shelter, sex and other physical needs); security (protection of physical and/or emotional harm) and social relations (affection, belonging, acceptance and friendship). At the higher levels, he places affection needs (self-esteem, autonomy, achievement and external esteem aspects such as status, people's recognition and attention) and those related to self-realization (to be what one wants to be, selfsatisfaction). This theory says that needs emerge when the immediate lower level has been satisfied (Maslow, 1991).

More recent job satisfaction definitions are those of Peiro et al., who define job satisfaction as an attitude or set of attitudes developed by the person towards their work situation (Peiro et al., 1995). Same as Robbins, who also said that it develops from the dialectical interrelation between the workers' perception and their work characteristics (Robbins, 1998).

We will consider that job satisfaction is the workers' attitude towards their work, which theoretical construction is always in process and which results from the relationship between their individual (knowledge, beliefs, needs, expectations) and social contexts (environment where they live and work), as well as from their adaptation to the work they perform.

Quantitative studies show satisfaction elements of "typical" work such as promotional opportunities (Delgado García et al., 2012), the salary (Mahendran and Devanesan, 2013) and work engagement (Rico, 2012).

On the other hand, qualitative studies show the subject's perspective. For example, the one of the Spanish construction workers, who declare that their work is "satisfactory, fun and fantastic", because they have different kinds of tasks and they feel that their work is recognized (Navarro et al., 2012). Or the British nurses, who comment that when they are allowed to prescribe drugs, their responsibility increases, but also their job satisfaction (Cousins and Donnell, 2012). Or the Mexican occupational health physicians who perceive stress as a job satisfaction element because this means that they have the responsibility and recognition of their work (López-García and Aguilera-Velasco, 2016).

That is the reason to conduct this research, in order to analyze the construction of job satisfaction of the workers of the creative industries in Mexico City.

\section{Materials and Methods}

The qualitative methodology of the grounded theory was chosen to address this study, described by Strauss and Corbin, whose basic concepts are theoretical sampling and theoretical saturation; the constant comparative method; open, axial and selective coding; memos and theoretical sensitivity. The Grounded theory builds a theory rather than testing an expert's theory. It emerges from data analysis and is based on the fieldwork to understand findings (Patton, 2001).

The strategy of theoretical sampling that (Strauss and Corbin explained as data collection, guided by the concepts and derived from the theory being built, was considered (Strauss and Corbin, 2002).

In this research, the selection criteria for the participants was determined by the facts that they were independent artists, who worked without an employment contract for at least three months, who lived predominantly with the profit their creative work and who lived in Mexico City.

Finally, the study was conducted on ten creative arts workers: Five male and five female. All of them are single and from 26 to 41 years old, with an average of 34 years. Regarding the academic level, $60 \%$ had a Bachelor's degree and $20 \%$ a postgraduate degree and all of them have extensive preparation in their area, acquired by working as apprentices with artists with greater experience.

In-depth interviews were used, which follow the model of a regular conversation, in which the researcher seeks to know the perspective of the interviewees: How they live, feel and think. The interview for this research used open and generating questions that allowed participants to answer freely and the researcher to delve into the answers. Some examples of the questions were: Could you please describe yourself? What's a normal work day like for you? What satisfaction does your work provide?

The interviews were conducted in the workspaces occupied by these workers and were recorded over the phone. Each of the interviews was conducted in a single session. Its average duration was of $50 \mathrm{~min}$. They were then transcribed in Word format and saved in a file.

For the analysis, a hermeneutic sheet was used in the Atlas.ti program for all the interviews conducted, the most important quotes were selected and the codes were obtained. These were integrated into categories, which formed the dimension of the job satisfaction of these participants.

\section{Results}

125 codes were found, which were grouped into six categories that eventually integrated the dimension of job satisfaction of these workers (Fig. 1). 


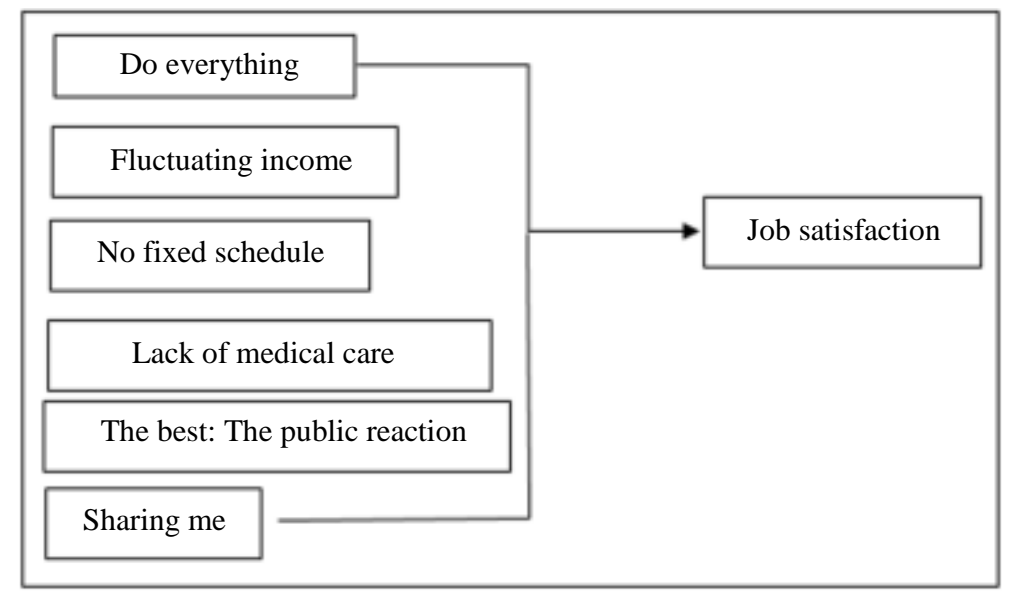

Fig. 1: Job satisfaction categories

The six categories with the number of codes included in them are the following.

\section{Do Everything (28 Codes)}

They stated that, to be an artist, they must diversify and carry out multiple activities, "do everything". Among the basic work activities, it was included: Sculpture, animation for short films, advertising, painting, drawing, musical performance and composition, dancing and singing.

All participants declared that they carried out complementary activities to secure their maintenance and, paradoxically, to finance their artistic projects. These were, for instance, plan design, carpentry, curatorship for cultural events, teaching, acting, modeling, taxi driving, food processing and sales.

\section{Fluctuating Income (29 Codes)}

"On a creative level, the lack of fixed income was a burden", they said. Everyone mentioned that their economic income changes day by day, that it is very "fluctuating". All of them have received at some point in their working life, government scholarships with a maximum duration of three years. They have also had scholarships for graduate studies. However, the supply of them varies greatly and there is never the security that they will continue with that income for a long time. Family support is often used, if possible.

Occasionally, they said they signed limited-time contracts with payment for fees to participate in festivals, or for "custom work", with informal payment, without a fixed contract and they receive payment only after they have delivered the product.

Those dedicated to painting declared that they work with "gallerists or dealers", who "charge" for their sale services, up to $50 \%$ of the profit obtained. Finally, they feel that their success as artists did not guarantee them a better income.

\section{No Fixed Schedule (19 Codes)}

Regarding their working hours, they explained that they require rest periods, which "are part of the creative process". They commented, "Sometimes, I spend time just reflecting and waiting, but others I don't even realize I'm still working and I forget to rest". Therefore, they like to be freelancers, because they can use their time as they wish.

\section{Lack of Medical Care (9 Codes)}

They mentioned "stress" as a work health effect "because they have very different tasks in many projects" and accidents that may arise in their very diverse workplaces. They said that they did not have any kind of health care, social security and occupational health benefits; except at some festivals, public events where they must have emergency medical service during the event. They commented, "if anything happens to us at work, there's no insurance for medical service or sickleave payments. We must take care of ourselves".

\section{The Best: The Public Reaction (23 Codes)}

They explained that one of their main satisfaction elements is the people's recognition of their work. They said it's interesting for them to see "something different" in their appreciations, not the same as their creating objective. Also, that their greatest satisfaction was "when people became involved and began to imagine".

But on the other side, as they said, "We have to educate people, they shouldn't think it's boring" and one of the painters stated, "I am open to negative criticism, but... it's very hard to accept it".

\section{Sharing Me (17 Codes)}

They said they find it very satisfying and even "addictive," to be "in a constant discovery". They declared that their work is a personal quest and that "all 
the time they are immersed in a whirlwind of sensations." However, they feel they are in a difficult situation because sometimes they have plenty of inspiration, but in others, they can't imagine anything.

They concluded "I like my work, it is part of me" and "I love sharing myself, but it could be better in other working conditions".

\section{Discussion}

Participants in this study are entrepreneurs in the creative economy, the one that was promoted as an alternative to overcome the economic and social difficulties of capitalism. However, they are immersed in precariousness, such as Mora and De Oliveira's precarious work regarding synthetic index states; with lack of stability, enough salary and social protection (Mora and De Oliveira's, 2009).

The temporality and lack of stability in the artist's work, their "fluctuating" income and the low economic retribution that they receive for their work are evident. That's why they must do many tasks, to support themselves and even to finance their artistic activities, despite the high preparation required from them. However, these young people (average age 34) like the flexibility of their schedule, which depends on their creativity and they claim that in fact, they do not expect greater retribution, even if they succeed in their creative work.

We can see that, as Maslow postulated, these workers value more the fulfillment of their needs at higher levels, such as autonomy, achievements, people's recognition and personal realization, than those located at the basic levels, related to physiological and security needs. They feel they can survive with a minimum income and are satisfied if they have the opportunity to perform their artistic activity (Maslow, 1991). These differ from "typical" work satisfaction elements (salary, promotion) mentioned in quantitative research (Mahendran and Devanesan 2013; Delgado García et al., 2012; Rico 2012).

Besides, our results are consistent with Peiro et al. definition because their job satisfaction results from the attitude (knowledge and belief), which they have developed towards their work and even though it has many disadvantages, it allows them to do what they love, as well as to develop themselves (Peiro et al., 1995).

\section{Conclusion}

The results show that satisfaction elements differ from those stated for formal work. They refer to autonomy, achievements, recognition and personal development as predominant factors in the theoretical construction that these workers make of their job satisfaction.

Despite this special construction of job satisfaction of creative workers, it is important to value the impact that informal work and precariousness have on their quality of work-life and health in order to propose alternatives to improve them.

About the methodology, the Grounded Theory, we can conclude that its methodological rigor allowed to systematize the research, making easy to analyze the interpretative data. It is important to note that, as in any qualitative research, the results cannot be generalized.

\section{Acknowledgment}

There was neither any financial support, nor technical assistance to report.

\section{Ethics}

This article is original and contains unpublished material. The corresponding author confirms that there are no ethical issues involved.

\section{References}

Cousins, R., \& Donnell, C. (2012). Nurse prescribing in general practice: a qualitative study of job satisfaction and work-related stress. Family Practice, 29(2), 223-227.

Delgado García, D., Inzulza González, M., \& Delgado García, F. (2012). Quality of life at work: Health Professionals Clinica Rio Blanco and Center Especialidades médicas. Medicina y Seguridad del Trabajo, 58(228), 216-223.

INEGI. (2020). Encuesta Nacional para la Ocupación y el Empleo de México (ENOE). Instituto Nacional de Estadística $\quad \mathrm{y}$ Geografía. https://www.inegi.org.mx/programas/enoe

García Canclini, N., Cruces, F., \& Urteaga, M. (2012). Young, urban cultures and digital networks. Emerging practices in the arts, publishing and music.

Gomes, C. (2018). The creative economy and the cultural and creative industries: a post-capitalist alternative? XV International Geocryptic Colloquium: The social sciences and the building of a post-capitalist society. Barcelona, Spain. http://www.ub.edu/geocrit/XV-

Coloquio/ChristianneGomes.pdf

López-García, M.C., \& Aguilera-Velasco, M.A. (2016). Stress in the theoretical construction of job satisfaction in occupational health physicians in Mexico City. Revista de la Facultad de Ciencias en Salud UDES, 3(2), 113-120. http://dx.doi.org/10.20320/rfcsudes.v3i2.203

Mahendran, M., \& Devanesan, P. (2013). Job stress and job satisfaction among employees of insurance companies. Golden Research Thoughts, 3(3), 1-5. 
Maslow, A. H. (1991). Motivation and Personality. India: Pearson Education India.

Mora, M., \& De Oliveira, O. (2009). Degradation of wage employment at the dawn of the 21st century: Costa Rica and Mexico. Papeles de Población (Universidad Autónoma del Estado de México), 15(61), 195-231. http://www.scielo.org.mx/scielo.php?script=sci_artt ext\&pid=S1405-74252009000300009

Navarro, E., Roche, H., \& Fuentes del Burgo, J. (2012). Do we know who we work with?: qualitative study on the work and job satisfaction of building officials. Spain: Polytechnic University of Valencia.

Patton, M.Q., 2001. Qualitative research and evaluation methods. Sage Publication Inc., E.U.A.

Peiro, J. M., González-Romá, V., Bravo, M. J., \& Zurriaga, R. (1995). The measure of job satisfaction. Ansiedad y Estrés, 1 (2-3), 231-253. https://dialnet.unirioja.es/servlet/articulo?codigo $=42$ 02522
Rico, P. (2012). Job satisfaction of employees in Spain. Revista de Métodos Cuantitativos para la Economía y la Empresa, 14, 137-158. https://www.researchgate.net/publication/28603139 6_Job_satisfaction_of_employees_in_Spain

Robbins, M. (1998). Organizational behavior. Mexico: Prentice Hall. http://www.rim.edu.bt/wpcontent/uploads/2014/09/OBCDFM6.pdf

Strauss, A., \& Corbin, J. (2002). Bases de la investigación cualitativa: técnicas y procedimientos para desarrollar la teoría fundamentada. Colombia: Universidad de Antioquía Editions.

UNESCO Mexico. (2014). Report on the Creative Economy. United Nations Development Programme (UNDP): Expand local development channels special edition. http://www.unesco.org/culture/pdf/creativeeconomy-report-2013-is.pdf 